\title{
JOVENS EM MERCADOS DE TRABALHO EM MUDANÇA: INDICAÇÕES A PARTIR DA TRAJETÓRIA DE DOIS GRUPOS GERACIONAIS
}

\author{
ÂNGELA BORGES*
}

\begin{abstract}
RESUMEN
El artículo aborda la constitución de las trayectorias laborales de jóvenes varones de un barrio periférico. El planteo teórico-metodológico parte de concebir a las trayectorias como un punto de cruce entre lo estructural y lo biográfico, entendiendo que los procesos de transición lineal de los jóvenes se han resquebrajado y requieren de miradas analíticas que consideren las múltiples esferas de la vida. Por esta razón, la investigación estudia las imbricaciones entre diversas esferas que, en el juego de sus interdependencias, dan forma a las trayectorias juveniles: la educación, la familia, el barrio y los grupos de pares. En esta línea, se elabora una tipología que surge del análisis empírico y que aparece como un hallazgo relevante para dilucidar la manera en que jóvenes de un mismo medio sociocultural configuran subjetividades y delinean recorridos divergentes.
\end{abstract}

PALABRAS CLAVE: JOVENS, MERCADO DE TRABALHO, DESEMPREGO, GRUPOS GERACIONAIS

* Brasileira, doutora em Ciências Sociais pela Universidade Federal da Bahia (2003); professora do Programa de Pós-graduação em Políticas Sociais e Cidadania da Universidade Católica do Salvador (UCSal). Atualmente coordena o GT População e Trabalho da Associação Brasileira de Estudos Populacionais e integra as equipes do projeto Metrópoles na atualidade brasileira: A Região Metropolitana de Salvador (PRONEX, FAPESB, CNPQ) e da rede de pesquisadores congregados no Observatório das Metrópoles incluído no Programa Institutos Nacionais de Ciência e Tecnologia (INCT/CNPQ/FAPERJ/Observatório das Metrópoles).

E-Mail: angelborges@uol.com.br. 


\title{
JÓVENES EN MERCADOS DE TRABAJO CAMBIANTES: INDICACIONES A PARTIR DE LA TRAYECTORIA DE DOS GRUPOS GENERACIONALES
}

\begin{abstract}
RESUMO
Este trabajo busca comprender el patrón de entrada y permanencia de los jóvenes en el mercado de trabajo urbano brasileño engendrado por la restructuración productiva de la década de 1990. Basados en los datos de la Encuesta Nacional por Muestreo de Viviendas (PNAD) (Pesquisa Nacional por Amostra de Domicílios en portugués), se observaron en dos grupos generacionales abiertos (jóvenes que tenían entre 15 y 19 años y entre 20 y 24 años al comienzo de la década) la relación escuela-trabajo, las tasas de actividad y de desempleo, las formas de inserción, la participación en el sistema de pensiones y los réditos en el período 1992-2006, y para evaluar de mejor manera el carácter de los cambios, se comparó la situación de esos grupos generacionales con la de los que eran jóvenes en el año 2011. Los resultados evidencian, no sólo que una parte de los jóvenes está siendo forzada a una inserción tardía, sino que también, a la pérdida de las calificaciones adquiridas, al aprisionamiento en ocupaciones precarias y al desaliento, como consecuencias sociales y personales extremadamente graves.
\end{abstract}

PALABRAS CLAVE: MERCADO DE TRABAJO, DESEMPLEO, GRUPOS GENERACIONALES

\section{YOUTHS FACED WITH A CHANGING LABOR MARKET: INDICATIONS BASED ON THE PATH OF TWO GENERATIONAL GROUPS}

\begin{abstract}
This paper seeks to understand the pattern of entry and permanence of young people in the Brazilian urban labor market engendered by the productive restructuring in the 1990's. Based on the data from the National Household Sample Survey (PNAD) (Pesquisa Nacional por Amostra de Domicílios in Portuguese), school-work relationship, activity and unemployment rates, forms of insertion, participation in social security systems and the yields in the period 1992-2006 were observed in two open generational groups (young people aged between 15 to 19 and between 20 to 24 at the beginning of the decade). In order to evaluate better the nature of these changes, the status of these generation groups was compared to the ones who were young in 2011. The results point out that not only a part of these young people is forced to a late insertion, but also to the loss of the acquired qualifications, being stuck in precarious occupations and subject to discouragement, with extremely severe social and personal consequences.
\end{abstract}

KEY WORDS: LABOR MARKET, UNEMPLOYMENT, GENERATIONAL GROUPS 


\section{INTRODUÇÃO}

HISTORICAMENTE, MESMO EM FASES de expansão da economia, a entrada dos jovens no mercado de trabalho e a conquista de uma posição estável neste mercado foram marcadas por dificuldades e tensões. No Brasil, a partir de 1990, no bojo da reestruturação produtiva e do re-desenho do padrão de desenvolvimento, essas dificuldades e tensões tornaram-se mais agudas, e foram explicitadas nas taxas de desemprego, que, em alguns momentos, chegaram a alcançar $1 / 3$ ou mais do grupo etário de transição da adolescência para a juventude, e no retardamento do ponto de inflexão dessas taxas, que deste modo ainda se mantêm muito elevadas entre os jovens adultos.

Desemprego juvenil mais elevado, com taxas sempre muito superiores à dos adultos, e a maior presença de jovens entre os desempregados em termos relativos são fenômenos normais, pois a idade constitui-se num dos atributos relevantes na determinação das chances de inserção no mercado de trabalho.

Tal relevância deriva da relação particular que os indivíduos têm com a atividade produtiva em cada fase da vida, relação essa que, embora variando de uma sociedade para outra, ao longo do tempo, entre as classes e, ainda, entre os gêneros, tende a ser mais forte nas duas ou três primeiras décadas da idade adulta, isto é, entre os 20 e os 50 anos e, sobretudo para os homens, ${ }^{1}$ quase impositiva. Nas sociedades capitalistas, a variável idade é particularmente fundamental na configuração das preferências dos empregadores, as quais moldam e, ao mesmo tempo, são moldadas pelas normas sociais vigentes, reforçando desse modo o papel central desempenhado pelos adultos jovens na força de trabalho diretamente subordinada ao capital. Essas preferências são relevantes ainda na segmentação dos trabalhadores em força de trabalho primária e secundária, uma clivagem que não é neutra em relação à idade (nem ao gênero), sendo, pelo contrário, em boa medida, informada pelos valores e normas que, numa dada sociedade e num determinado tempo histórico, estabelecem de forma mais ou menos rígida os papéis a serem desempenhados por homens e mulheres em cada um dos ciclos da vida.

Em síntese, o perfil etário dos ocupantes dos lugares existentes no mercado de trabalho vai ser resultante tanto de fatores objetivos, a exemplo das necessidades do processo de produção e da composição

1 Embora cada vez mais também para as mulheres. 
da oferta de força de trabalho em cada contexto e em cada tempo histórico, como de valores e estereótipos dominantes na sociedade e das normas, valores e instituições que regulam as entradas e saídas do mercado de trabalho e os termos da contratação e dispensa de trabalhadores.

Para compreender essa importância que as idades assumem no mercado de trabalho, é necessário considerar também que, neste mercado, de forma mais explícita do que em outros espaços do mundo social, as idades são socialmente construídas (Bourdieu, 1983) e, mais que isso, como afirma Langevin, o mercado é «um dos lugares onde se elaboram as regras de legitimação do valor das idades» (Langevin, 1998:139). Nele, a juventude, a maturidade e a velhice são conceitos que não remetem necessariamente à idade biológica, expressando, pelo contrário, conflitos geracionais e interesses vários, em especial do capital e do Estado, que usam e abusam do poder de nomear para decretar, conforme lhes seja mais conveniente, a «imaturidade» ou, ao contrário, a «contemporaneidade» dos mais novos — mesmo que não sejam tão jovens assim- e o «envelhecimento» ou a «experiência virtuosa»dos mais velhos - aqui também não importando se a idade desses trabalhadores permite enquadrá-los na categoria de velhos, definida em função de parâmetros biomédicos. ${ }^{2}$

No mercado de trabalho, este processo de construção social das idades é particularmente evidente no momento da integração das novas gerações no mundo do trabalho: os adolescentes e jovens passam sempre por período mais ou menos longo de procura de emprego, constituem o segmento mais facilmente demitido em momentos de retração da demanda e de ajustes e quanto mais jovens, mais são considerados força de trabalho secundária (Offe, 1989), à qual são destinados os postos de trabalho menos estratégicos e menos exigentes em termos de qualificação e experiência.

2 Vários fenômenos observados no mercado de trabalho deixam claro o seu papel na construção das idades, assim como a importância das idades no estabelecimento de clivagens importantes. Por exemplo, o envelhecimento profissional varia de acordo com a profissão ou ocupação: uns começam a trabalhar mais cedo e envelhecem também mais cedo (como os operários), enquanto outros ingressam e saem do mercado mais tarde, e o seu envelhecimento é mais prolongado e valorizado (como os professores universitários), sendo esta diferença coletivamente legitimada por normas sociais e culturais (Langevin, 1998). 
Além disso, embora necessários e amplamente recrutados pelas empresas, a contratação dos jovens - sobretudo nas faixas de menor idade - com frequiência é feita sob formas que fogem do contrato padrão, ${ }^{3}$ inclusive aquelas que implicam na burla de direitos, consideradas, pelos empregadores, como mais «adequadas» para trabalhadores ainda em fase de formação, de aprendizagem para a vida ativa e cujo trabalho tende a ser visto, na sociedade, como uma atividade secundária comparativamente a outras que desempenham, a exemplo dos estudos.

Outro elemento cuja consideração prévia é fundamental na discussão da relação do jovem com o mercado de trabalho é o papel determinante das variáveis macroeconômicas, isto é, da situação da economia e do mercado de trabalho no momento da entrada de uma dada geração no mercado de trabalho, pois terão influência marcante na trajetória futura desse jovem. Por esta razão, o recurso à análise do percurso de trabalho e estudo de grupos geracionais abertos ${ }^{4}$ (GGAs) aqui utilizado pode aportar importantes contribuições para o conhecimento do impacto, sobre os trabalhadores, das transformações sofridas pela economia brasileira na última década do século XX, na medida em que este tipo de análise permite captar tanto os efeitos de idade quanto os efeitos de período ${ }^{5}$ (mudanças no contexto macroeconômico e seus reflexos no mercado de trabalho). A consideração dos efeitos de período é particularmente relevante em contextos de mudanças estruturais, quando as teorias que buscam explicar a situação dos jovens no mercado de trabalho a partir do modus operandi das empresas e das especificidades da mão-de-obra juvenil já não conseguem dar conta do elevado desemprego que atinge este segmento, nem das barreiras por ele encontradas para conquistar uma posição estável nesse mercado.

Neste artigo, procura-se compreender melhor o caráter das mudanças no âmbito do trabalho engendradas pela reestruturação produtiva dos anos 90 do século passado, observando em que medida elas podem estar configurando um novo padrão de entrada e permanência no mercado de trabalho a partir da análise das mudanças experimentadas por dois grupos geracionais abertos, os quais, na ausência de pesquisas longitudinais sistemáticas, se constituem em um recurso válido

3 No caso brasileiro, a Consolidação da Legislação Trabalhista (CLT) e o Estatuto do Funcionário Público.

4 Grupos formados por indivíduos de uma mesma idade, afetados pela mortalidade e pela entrada e saída de pessoas por migração.

5 Ver Rios-Neto et al., 2003. 
para a análise pretendida. $\mathrm{O}$ estudo baseia-se em dados da Pesquisa Nacional por Amostra de Domicílios (PNAD)e toma como referência espacial o Brasil urbano. Ou seja, trabalha-se com uma média referida a mercados de trabalho bastante heterogêneos: os grandes mercados de trabalho metropolitanos do Sudeste, os mais estruturados do País, outros grandes mercados metropolitanos distribuídos em todo o território nacional e uma miríade de médios e pequenos mercados locais, na maioria dos casos pouco dinâmicos e não estruturados, com reduzida proporção de postos de trabalho protegidos. Observe-se que a utilização da média do Brasil urbano naturalmente faz com que processos muito marcantes nos mercados de trabalho metropolitanos, os mais estudados, apareçam aqui bem mais atenuados.

Os grupos geracionais selecionados são formados pelos jovens que tinham entre 15 e 19 anos (GGA 1) e entre 20 e 24 anos (GGA 2) em 1992. Busca-se captar, portanto, as trajetórias dos primeiros grupos de jovens que vivenciaram a experiência de inserção no mercado de trabalho a partir do momento em que o processo de reestruturação produtiva vai se tornando sistêmico ${ }^{6}$ no Brasil. São analisadas, para os dois grupos, a relação escola-trabalho, as taxas de atividade e de desemprego, as formas de inserção, a participação no sistema previdenciário, a jornada de trabalho e os rendimentos, no período 1992-2006. Finalmente, para melhor avaliar o caráter dessas mudanças, comparase a situação desses grupos etários em 1992 com a dos que eram jovens em 2011.

Não sendo a juventude homogênea, a análise da sua relação com o trabalho deve considerar a diversidade de trajetórias que resultam das suas múltipas clivagens (classe, gênero, cor, escolaridade, etc) e a interação entre elas. Na impossibilidade de abarcar todas estas dimensões nos limites de um artigo, a análise centrar-se-á nas diferenças de gênero, uma das principais clivagens na relação dos jovens com o trabalho e na transição para a vida adulta.

6 No Brasil, a reestruturação produtiva iniciou-se nos últimos anos da década de 80, nos setores mais expostos à concorrência internacional, a exemplo da petroquímica. Mas é a partir dos anos 90, com a abertura da economia, que todas as empresas, de todos os setores, empreendem ajustes para adequar-se aos novos termos da competição intercapitalista. Sobre o assunto, ver Druck (1999); Druck e Franco (2007) e Guimarães (2004). 


\section{Algumas CONSIDERAÇÕES SOBRE O PERÍODO ESTUDADO}

No Brasil, como sabido, o ajuste macroeconômico dos anos 1990, pautado nas recomendações do Consenso de Washington, foi acompanhado por uma reestruturação produtiva selvagem que se seguiu à abertura da economia, realizada sem qualquer planejamento ou política industrial, resultando em baixas taxas de crescimento durante quase toda a década, com impactos profundos sobre o mercado de trabalho. Esses impactos se explicitaram na rápida elevação das taxas de desemprego e na precarização dos vínculos empregatícios, processos que atingiram todos os trabalhadores, mas com maior intensidade os jovens (Pochmann, 1998), os primeiros a serem demitidos, pelo baixo custo dessas demissões e pelo reduzido investimento realizado pelas empresas nesses trabalhadores. Ademais, com a rápida elevação do desemprego e queda generalizada dos salários, os adultos passaram a disputar com os jovens os postos de trabalho com remuneração mais baixa do núcleo formal da economia, deslocando-os para os empregos mais precários e instáveis na cascata de subcontratação e nos pequenos negócios.

Além de enfrentarem um desemprego elevado, os jovens trabalhadores e aqueles em busca do primeiro emprego se defrontaram com um mercado de trabalho com exigências crescentes de escolarização formal e de formação contínua, mas que, simultaneamente, passou a oferecer recompensas declinantes às credenciais do sistema educacional. Essa contradição está relacionada com a rápida expansão do número de diplomados nos níveis médio e superior —em parte dos casos oriundos de instituições com ensino de baixa qualidade - exatamente quando a reestruturação produtiva e o novo perfil de inserção da economia brasileira no cenário mundial (produção de commodities e de bens com baixo valor agregado e baixo padrão tecnológico) levaram à contração do número de postos de trabalho mais qualificados e mais bem remunerados.

Como resultado dessa combinação de fatores, a partir de então três fenômenos tornam-se freqüentes na relação dos jovens brasileiros com o trabalho: elevado desemprego, inclusive para aqueles que estudaram; situações de sobrequalificação no trabalho; e emigração, sobretudo de indivíduos com escolaridade igual ou superior ao grau médio. Depois de mais de dez anos de destruição de empregos - principalmente daqueles com carteira assinada-, a economia brasileira passou a registrar uma recuperação do emprego no início dos anos 2000, com 
a retomada do crescimento viabilizada, principalmente, pela desvalorização do dólar e pela expansão generalizada da economia mundial - pela primeira vez depois dos anos 60 do século XX-, a qual provocou uma elevação da demanda pelos produtos da pauta de exportação brasileira, com efeitos extremamente positivos sobre as atividades do agronegócio. Além disso, mesmo que tímida, a recuperação dos salários, especialmente o salário mínimo, somada às transferências governamentais de renda para os segmentos mais carentes e à ampliação do crédito ao consumidor, repercutiram positivamente sobre o consumo interno, reforçando a espiral do crescimento com efeitos positivos sobre a geração de emprego.

Como essa recuperação do emprego ocorreu, em grande parte, nos segmentos mais organizados da economia, como a indústria de transformação, observou-se também, pela primeira vez depois da reestruturação dos anos 1990, o aumento do número de postos de trabalho socialmente protegidos (com carteira assinada), porém dentro do perfil salarial rebaixado que caracteriza as economias centradas no baixo custo - sobretudo o custo do trabalho-, que vai se configurando como o novo modelo de desenvolvimento do País. Assim, entre 2002 e 2006, a totalidade do saldo de empregos com carteira assinada gerado nos mercados de trabalho das áreas urbanas do Brasil situava-se abaixo da faixa salarial de até dois salários mínimos, reforçando a histórica concentração da estrutura upacional do país nas faixas de baixos rendimentos (Dedecca, 2006). Com algum abalo em 2009, repercutindo a crise de 2008, essas tendências se mantiveram até 2011, quando os jovens que compõem os grupos etários estudados se defrontam com um mercado de trabalho totalmente distinto daquele no qual os jovens de 1992 se inseriram.

No ambiente macroeconômico dos anos 90 e dos primeiros anos 2000, as dificuldades de acesso ao trabalho, as reduzidas perspectivas profissionais e as limitadas oportunidades de autonomia financeira experimentadas pelos jovens foram colocadas no centro do debate sobre a questão social brasileira, tal como já havia ocorrido nos países centrais, com o fim do ciclo de expansão do pós-guerra denominado fordismo. No caso brasileiro, a centralidade dessa questão foi reforçada pelas suas consequiências negativas sobre os níveis de exposição a 
riscos sociais extremamente graves ${ }^{7}$ de largos contingentes de jovens de famílias pobres, os mais fortemente atingidos pelas mudanças do mercado de trabalho.

\section{OS DOIS GRUPOS GERACIONAIS}

Os grupos geracionais selecionados neste estudo correspondem aos grupos qüinqüenais $^{8}$ entre 15 e 19 anos e entre 20 e 24 anos em 1992, formados por jovens nascidos entre o ano de 1968 e o final dos anos 1970. Um período que teve o seu início marcado por alguns anos de vigoroso crescimento econômico e que terminou com o colapso de um modelo fincado em volumosos investimentos e forte intervenção do Estado, no contexto da ditadura militar, através dos Planos Nacionais de Desenvolvimento financiados pelo endividamento externo e por uma brutal contenção dos salários de base.

Entre 1968 e 1977, quando nasceram os primeiros e os últimos integrantes dos grupos geracionais estudados, o Produto Interno Bruto (PIB) per capita mais do que dobrou. Tal crescimento resultou em uma elevadíssima concentração da renda, com o índice de Gini alcançando 0,625 no final dos anos 1960 . Nos trinta anos seguintes, a concentração da renda do trabalho permaneceu elevada, com redução algo significativa apenas na segunda metade dos anos 2000, em consequência da recomposição do salário mínimo, das transferências de renda para os mais miseráveis e do achatamento do leque salarial, mas, mesmo assim, no final do período analisado este indicador ainda era de 0,569.

Os jovens que tinham entre 20 e 24 anos, em 1992, nasceram entre 1968 e 1973, em pleno «milagre econômico» do regime autoritário, quando o PIB brasileiro registrava taxas de crescimento em torno de $10 \%$ a.a. e as oportunidades de emprego/ocupação eram amplas para os jovens de então ${ }^{9}$, parte deles pais daqueles que hoje formam os

7 Tais riscos se acentuam e se explicitam nas áreas urbanas do Brasil, e não apenas nas metrópoles, como o tráfico e o consumo de drogas e a criminalidade violenta.

8 Cinco anos, inclusive os extremos.

9 Evidentemente, a maior parte das ocupações geradas nesse período era de baixa qualidade, mal remunerada e/ou precária, mas ainda assim, assegurava uma trajetória para a idade adulta menos problemática do que a vivenciada pelos jovens de hoje. Não deve ser esquecido que para uma parte daqueles jovens os empregos precários então existentes constituí- 
grupos geracionais estudados. Ressalte-se, ainda, que além do acesso mais fácil a um emprego, a expansão do número de postos de trabalho mais bem remunerados e com possibilidades de carreira no setor público e na iniciativa privada propiciou, a uma parcela não desprezível da geração de jovens que vivenciou o «milagre», amplas oportunidades de mobilidade sócioocupacional ascendente.

Já os adolescentes com idades entre 15 e 19 anos em 1992 nasceram em um país cuja economia ainda crescia rapidamente (média de $8,0 \%$ a.a. de 1973 a 1977), mas que já apresentava claros sinais do esgotamento do modelo de crescimento, que se tornaram mais visíveis no final dos anos 1970/início dos 1980, quando a taxa de crescimento do PIB caiu para 3,5\% a.a. como resultado de uma profunda recessão nos últimos anos do período. Os que eram jovens em 1992 se beneficiaram da ampliação do sistema educacional público e privado, integrando uma geração com escolaridade bem mais elevada do que a dos seus pais. Ainda assim, naquele ano, apenas 4,6\% dos homens de 15 a 19 anos e $20,8 \%$ dos que tinham entre 20 e 24 anos tinham concluído o Ensino Médio ou estavam cursando a universidade, e o percentual dos que já haviam concluído o grau de ensino mais elevado não ultrapassava $1,4 \%$. Os indicadores femininos são um pouco melhores (com Ensino Médio completo, 6,4\% do grupo de 15 a 19 anos e 27,7\% dos que tinham entre 20 e 24 anos). Neste grupo, 2,1\% possuíam diploma de nível superior.

Ou seja, no início do período estudado, a maior parte dos integrantes dos dois grupos geracionais tinha escolaridade inferior ao Ensino Médio, a qual já vinha sendo colocada como pré-requisito para a maioria dos postos de trabalho de melhor qualidade, em especial no segmento organizado da economia. Nos anos seguintes, muitos desses jovens conquistaram níveis mais elevados de escolaridade, mas uma proporção elevada deles carregou um déficit de escolaridade para a idade adulta: em 2006, tinham o Ensino Médio completo ou mais $43,8 \%$ dos homens e 50,2\% das mulheres do grupo de 15 a 19 anos em 1992. Já o grupo de 20 a 24 anos (como visto, majoritariamente fora da escola em 1992), com idades entre 34 e 38 anos em 2006, os percentuais dos que tinham alcançado o grau médio ou mais eram ainda mais baixos: $39,5 \%$ e 43,9\%, respectivamente. São, portanto, grupos geracionais que apesar de mais escolarizados do que as geraç-

ram «portas de entrada» para melhores posições no sistema produtivo em expansão. 
ões anteriores, encontram-se em desvantagem em relação aos GGAs mais novos, que vivenciam o boom do ensino superior e de abertura deste grau de ensino às camadas mais pobres da população, como será mostrado mais à adiante.

Esses dois grupos constituem a primeira geração de jovens brasileiros, majoritariamente urbana, a enfrentar, de modo duradouro, condições extremamente adversas para conseguir e se manter em um emprego ou ocupação. Como foi observado, eles se depararam com um mercado de trabalho em rápida e profunda transformação: desemprego aberto elevadíssimo $-11,7 \%$ na média das regiões metropolitanas, segundo a Pesquisa Mensal de Emprego (PME) do Instituto Brasileiro de Geografia e Estatístrica (IBGE); postos de trabalho intensamente transformados e em contínua reconfiguração; novas e mais elevadas exigências em termos de escolaridade; e trajetórias profissionais truncadas, com desemprego recorrente e trânsito freqüente entre atividade e inatividade e entre espaços sócioocupacionais.

O início do período analisado foi marcado por baixo crescimento, em 1992 o PIB cresceu apenas 0,5\%, em decorrência de uma abertura indiscriminada e da inflação que alcançou $1.157 \%$, no acumulado do ano e permaneceu elevada ainda em 1993 e até meados de 1994, quando foi implementada a última etapa do Plano Real, que levou à estabilização monetária. As profundas diferenças entre o contexto macroeconômico e social no qual os jovens que constituem os dois grupos estudados vivenciaram as suas primeiras experiências no mercado de trabalho e aquele no qual seus pais, no passado, fizeram esta transição, resultaram em um acentuado distanciamento entre as referências e expectativas que lhes são transmitidas pela família e as condições objetivas que encontram para a realização destas expectativas.

Deste modo, os jovens dos anos 1990 viram-se desafiados a inventar seus próprios mapas cognitivos do mundo do trabalho, quando os do passado já não lhes serviam e quando a fluidez e ilegibilidade das relações de trabalho e das instituições do capitalismo contemporâneo tornam esta tarefa cada vez mais difícil e um esforço solitário de cada indivíduo, sobre quem o discurso neoliberal, hegemônico, descarrega toda a responsabilidade pelo sucesso ou fracasso profissional. Essas diferenças entre as experiências de gerações de jovens na sua relação com o trabalho traduzem as profundas transformações no mercado de trabalho e a sua análise é importante para a percepção dos fenômenos novos no âmbito do trabalho, mas também da cultura, da 
sociabilidade, do consumo, das relações familiares, dentre outros, e suas implicações para o futuro (Telles, 2006).

\section{AS TRAJETÓRIAS DOS DOIS GRUPOS GERACIONAIS (GGA)}

A seguir, para cada um dos dois grupos geracionais selecionados são apresentados alguns indicadores capazes de sinalizar a evolução, ao longo do período 1992-2006, da sua relação com a escola e com o trabalho e, para os que estavam ocupados, das condições dessa inserção. As taxas foram calculadas por sexo, de modo a permitir observar em que medida diferenças e desigualdades referidas ao gênero foram relevantes na trajetória desses jovens.

\section{a) Trajetórias masculinas}

Em 1992, nos dois grupos geracionais, a maioria dos jovens já trabalhava. Esta situação é mais marcante no grupo de 20 a 24 anos, onde $80,6 \%$ dos jovens já eram trabalhadores e $68,7 \%$ já não frequentavam a escola tendo, portanto, no trabalho a sua principal atividade. No grupo de 15 a 19 anos, 57,8\% também já trabalhavam, e os que apenas trabalhavam somavam mais de 1/3 desse Grande Grupo Ocupacional GGA, no mesmo ano. Entre os homens, em ambos os grupos, essa centralidade do trabalho evoluiu rapidamente com a idade, embora isso seja menos intenso no grupo mais jovem, onde as proporções dos que continuaram estudando até os 20-24 anos ou mesmo até os 25-29 anos, combinando ou não os estudos com o trabalho, eram mais significativas do que no grupo que tinha entre 20 e 24 anos, em 1992. Esta é uma tendência que vai ser acentuada nos GGAs que completaram de 15 a 19 anos nos anos seguintes e foram, como dito, mais beneficiados pela expansão da matrícula no nível médio e no ensino superior.

Corroborando essas informações, as taxas de atividade, já bastante elevadas no início do período analisado (90,3\% para os que tinham de 20 a 24 anos), também sobem rapidamente para os homens jovens dos dois GGAs observados, alcançando picos em torno de $95 \%$ em 2006. Em 1992, as taxas de desemprego dos dois GGAs eram bastante elevadas (respectivamente 15\% e 10,8\% para os mais jovens e para os mais velhos), mas para os dois grupos essas taxas caem de forma consistente com o passar dos anos, embora se mantenham num patamar muito alto até os 24 anos. Em 2006, quando a economia já voltara a crescer, registrando uma geração expressiva de novos postos de tra- 
balho, o grupo masculino de 15 a 19 anos em 1992 já tinha entre 29 e 33 anos de idade e a sua taxa de desemprego situava-se em 5,2\%. Já o grupo dos que tinham entre 20 e 24 anos no início do período alcançou, em 2006, idades entre 34 e 38 anos com uma taxa de desemprego de 4,2\%. Embora as duas taxas do final do período sejam ainda elevadas - sobretudo se comparadas com o quase pleno emprego vigente até o início dos anos 1980-, elas parecem sugerir que, para os homens, a exposição ao desemprego é fortemente influenciada pelo fator idade e se reduz sensivelmente a partir dos 30 anos de idade.

No entanto, é importante observar que outro indicador aponta em sentido contrário: em cada um dos grupos geracionais, o percentual de indivíduos do sexo masculino que "não estuda nem trabalha", sensivelmente superior à taxa de desemprego a partir dos 20 anos e que, ao contrário desta, não cai de modo marcante com o envelhecimento do GGA, alcançando, em 2006, 9,6\% para o GGA 1 e $8,2 \%$ para o GGA 2. Esses números, que sinalizam para a exclusão do mundo do trabalho de quase $10 \%$ dos homens jovens dos GGAs estudados, mostram a necessidade de estudos mais detalhados, aprofundados e longitudinais destes segmentos excluídos, desde a juventude, de dois dos principais integradores, a escola e o trabalho e, portanto, aparentemente mais expostos aos riscos sociais mais graves. Estudos que consigam ir além da simples caracterização sócio-demográfica deste segmento e sejam capazes de indicar: quem são eles? Onde e como vivem? Serão sempre os mesmos indivíduos ${ }^{10}$ ? Quais os fatores que estão determinando esta exclusão e qual a importância relativa de cada um deles? Em que medida e em quais circunstâncias esta exclusão configura-se como uma situação socialmente problemática e grave? Finalmente, parece importante investigar se o fenômeno e a sua magnitude são efetivamente novos, se nunca aconteceram no passado. ${ }^{11}$

10 Pesquisas amostrais como a PNAD, que trabalham com amostras diferentes, não permitem acompanhar as trajetórias de indivíduos e por esta razão não é possível afirmar, ainda que esta seja uma hipótese plausível, que uma parcela importante dos que «não estudam nem trabalham»é formada por um mesmo conjunto de indivíduos.

11 Quanto a esta indagação, estudo realizado por Cardoso (2007) sugere que este não é um fenômeno novo no Brasil. A autora agradece a gentileza do autor que lhe deu acesso aos originais do seu trabalho em vias de publicação. 
QUADRO 1: INDICADORES DE ATIVIDADE, DESEMPREGO, FORMAS DE INSERÇÃO E RELAÇÃO TRABALHO/ESCOLA, HOMENS, GRUPOS GERACIONAIS SELECIONADOS, BRASIL URBANO, 1992-2006

\begin{tabular}{|c|c|c|c|c|c|c|c|c|}
\hline IDADE EM 1992 & & & & & & 20 & 24 & \\
\hline Ano & 1992 & 1997 & 2002 & 2006 & 1992 & 1997 & 2002 & 2006 \\
\hline Idade & $\begin{array}{c}15 \text { a } \\
19\end{array}$ & $\begin{array}{c}20 \text { a } \\
24\end{array}$ & $\begin{array}{c}25 \text { a } \\
29\end{array}$ & $\begin{array}{c}29 \text { a } \\
33\end{array}$ & $\begin{array}{c}20 \text { a } \\
24\end{array}$ & $\begin{array}{c}25 \mathrm{a} \\
29\end{array}$ & $\begin{array}{c}30 \mathrm{a} \\
34\end{array}$ & $\begin{array}{c}34 \mathbf{a} \\
38\end{array}$ \\
\hline $\begin{array}{l}\text { Taxa de ativida- } \\
\text { de }\end{array}$ & 67.9 & 88.6 & 93.6 & 94.5 & 90.3 & 94.2 & 95.0 & 95.2 \\
\hline $\begin{array}{l}\text { Taxa de desem- } \\
\text { prego }\end{array}$ & 15.0 & 10.9 & 7.9 & 5.2 & 10.8 & 7.1 & 5.5 & 4.2 \\
\hline$\%$ ECC & 32.1 & 52.8 & 50.7 & 55.7 & 53.9 & 53.8 & 48.3 & 53.4 \\
\hline$\%$ ESC & 43.7 & 27.6 & 23.6 & 18.1 & 25.5 & 19.9 & 18.3 & 15.2 \\
\hline$\% \mathrm{CP}$ & 9.4 & 13.9 & 18.0 & 19.1 & 14.2 & 20.2 & 22.9 & 23.0 \\
\hline$\%$ Contribuintes $*$ & 17.7 & 41.1 & 50.6 & 57.9 & 45.1 & 52.3 & 53.9 & 58.3 \\
\hline Só estudam & 30.4 & 7.8 & 2.6 & 0.8 & 6.2 & 1.8 & 0.9 & 0.5 \\
\hline Só trabalham & 34.1 & 62.9 & 76.3 & 82.2 & 68.7 & 80.3 & 83.6 & 85.7 \\
\hline $\begin{array}{l}\text { Estudam e tra- } \\
\text { balham }\end{array}$ & 23.7 & 16.0 & 9.8 & 7.3 & 11.9 & 7.1 & 6.2 & 5.5 \\
\hline $\begin{array}{l}\text { Não estudam } \\
\text { nem trabalham }\end{array}$ & 11.8 & 13.3 & 11.2 & 9.6 & 13.2 & 10.8 & 9.3 & 8.2 \\
\hline $\begin{array}{l}\text { ECC - Empregado } \\
\text { Empregados sem } \\
\text { contribuem para a }\end{array}$ & $\mathrm{mc}$ & ia. & hada & ncio & $\begin{array}{l}\text { os } \mathrm{P} \\
\mathrm{ia} ; \mathrm{C}\end{array}$ & $\begin{array}{l}\cos \text { e } \\
\text { ribuil }\end{array}$ & $\begin{array}{l}\text { ilitare } \\
\text { - Pe }\end{array}$ & $\begin{array}{l}\text { ESC - } \\
\text { as que }\end{array}$ \\
\hline
\end{tabular}

FONTE: IBGE/PNAD.

Em síntese, os indicadores relativos aos jovens do sexo masculino mostram que apesar do desemprego elevadíssimo na transição da adolescência para a juventude, e mesmo durante uma boa parte desta, nos dois grupos geracionais abertos estudados a maior parte dos jovens de 1992 conseguiu se inserir na atividade produtiva, chegando à idade adulta com uma ocupação. Mas também mostram que, simultaneamente, um percentual não desprezível desses jovens parece não ter conseguido cumprir este tipo de trajetória.

Outros indicadores trabalhados permitem observar o processo de inserção no mercado de trabalho desses grupos geracionais e dizem algo sobre a qualidade esta inserção. O primeiro deles remete à «posição na ocupação» dos homens ocupados que compõem os dois grupos estudados e mostra que o acesso a um emprego protegido ${ }^{12}$ torna-

12 Inclui os trabalhadores «com carteira assinada» (ou registrados), os funcionários públicos e os militares. 
se menos difícil a partir dos 20 anos, mas que este espaço do mercado de trabalho urbano no Brasil é efetivamente bastante reduzido, conseguindo incorporar, em cada ponto da trajetória, no máximo, pouco mais da metade de cada grupo (em 2006, ano de forte recuperação do emprego registrado, estavam nesta posição $55,7 \%$ do grupo que tinha entre 15 e 19 anos em 1992 e $50 \%$ do grupo de 20 a 24 anos). O emprego precário, não registrado, constitui a principal forma de inserção dos adolescentes e jovens entre 15 e 19 anos, reduzindo a sua importância a partir dos 20 anos. Ainda assim, em 2006, encontravam-se neste tipo de ocupação nada menos que $18 \%$ dos homens adultos entre 29 e 33 anos, que compõem a GGA 1, e 15,2\% do GGA 2, com idades entre 34 e 38 anos no final do período.

Já a inserção por «conta própria», outra posição na ocupação importante nos mercados de trabalho urbanos do Brasil, tem um comportamento semelhante ao do emprego protegido: a proporção de trabalhadores com este tipo de inserção é baixa entre os muito jovens e aumenta com a idade, mas, para os grupos estudados, não chega a atingir $1 / 4$ do total de ocupados, o que evidencia a falácia do discurso do empreendedorismo como alternativa de inserção no mercado de trabalho, em especial quando ele é colocado como saída para o elevado desemprego juvenil. A conquista de uma posição estável em uma atividade por «conta própria» exige pré-requisitos que a maioria dos jovens trabalhadores ainda não dispõe: algum capital, domínio de um ofício ou profissão, rede de relações e toda a experiência e maturidade necessárias para disputar um espaço no chamado «setor informal», o qual, embora apresente menores «barreiras à entrada» do que o segmento organizado da economia, é bem mais restrito do que o imaginado pelos ideólogos do empreendedorismo (Borges, 2001). Além disso, para a maioria desses jovens ocupados «por conta própria», as chances de obter uma renda mensal próxima do rendimento médio dos empregados com carteira assinada seguem sendo bastante reduzidas, apesar das elevadas perdas salariais sofridas por estes trabalhadores.

Os indicadores acima comentados já são suficientes para mostrar o elevado grau de exposição a situações de precariedade das gerações que chegaram ao mercado de trabalho no bojo da reestruturação da economia e, logo, a reprodução ampliada deste traço estrutural do mercado de trabalho brasileiro. Outros indicadores podem ser agregados para evidenciar essa dimensão do trabalho juvenil como, por 
exemplo, o reduzido contingente que contribui para a previdência e a entrada tardia no sistema previdenciário da maioria dos jovens dos grupos geracionais estudados: no grupo de 15 a 19 anos em 1992, embora a maior parte já trabalhasse, o percentual de $50 \%$ de contribuintes só foi alcançado em 2002, tendo os jovens do sexo masculino do GGA 2 alcançado a marca de 52\% de contribuintes em 1997, em ambos os casos quando atingidas as idades entre 25 e 29 anos. Em 2006, quando os adolescentes e jovens de 1992, do sexo masculino, já estavam, respectivamente, nas faixas etárias de 29 a 33 anos e 34 a 38 anos, os percentuais de inseridos no sistema de previdência atingiram os pontos máximos para estes GGA s (aproximadamente 58\%) restando, portanto, inteiramente desprotegidos mais de $40 \%$ dos grupos estudados, a maioria candidata a integrar, na velhice, o público alvo dos programas governamentais de transferência de renda.

QUADRO 2: HORAS TRABALHADAS EM TODOS OS TRABALHOS, HOMENS, GRUPOS GERACIONAIS SELECIONADOS, BRASIL URBANO, 1992-2006

\begin{tabular}{|l|c|c|c|c|c|c|c|c|}
\hline \multicolumn{7}{|c|}{ Grupos Geracionais } \\
\hline & \multicolumn{7}{|c|}{15 a 19 anos em 1992 } & \multicolumn{3}{c|}{$\mathbf{2 0}$ a 2 anos em 1992 } \\
\hline Ano & $\mathbf{1 9 9 2}$ & $\mathbf{1 9 9 7}$ & $\mathbf{2 0 0 2}$ & $\mathbf{2 0 0 6}$ & $\mathbf{1 9 9 2}$ & $\mathbf{1 9 9 7}$ & $\mathbf{2 0 0 2}$ & $\mathbf{2 0 0 6}$ \\
\hline Idade & $\mathbf{1 5 - 1 9}$ & $\mathbf{2 0 - 2 4}$ & $\mathbf{2 5 - 2 9}$ & $\mathbf{2 9 - 3 3}$ & $\mathbf{2 0 - 2 4}$ & $\mathbf{2 5 - 2 9}$ & $\mathbf{3 0 - 3 4}$ & $\mathbf{3 4 - 3 8}$ \\
\hline $\begin{array}{l}\text { Horas } \\
\text { trabalhadas }\end{array}$ & & & & & & & & \\
\hline $\begin{array}{l}\text { Até 14 } \\
\text { horas }\end{array}$ & 2.7 & 1.2 & 1.2 & 1.0 & 1.1 & 0.9 & 1.0 & 1.2 \\
\hline $\begin{array}{l}\text { De 15 a 39 } \\
\text { horas }\end{array}$ & 18.0 & 11.0 & 10.0 & 9.9 & 9.7 & 8.4 & 8.5 & 9.6 \\
\hline $\begin{array}{l}\text { De 40 a 44 } \\
\text { horas }\end{array}$ & 38.0 & 40.7 & 37.6 & 40.9 & 41.1 & 38.5 & 37.7 & 40.3 \\
\hline $\begin{array}{l}\text { De 45 a 48 } \\
\text { horas }\end{array}$ & 21.3 & 23.9 & 23.6 & 21.9 & 24.0 & 23.9 & 22.1 & 20.9 \\
\hline $\begin{array}{l}\text { Mais de 48 } \\
\text { horas }\end{array}$ & 19.9 & 23.2 & 27.5 & 26.3 & 24.1 & 28.4 & 30.6 & 27.9 \\
\hline Total & $\mathbf{1 0 0 . 0}$ & $\mathbf{1 0 0 . 0}$ & $\mathbf{1 0 0 . 0}$ & $\mathbf{1 0 0 . 0}$ & $\mathbf{1 0 0 . 0}$ & $\mathbf{1 0 0 . 0}$ & $\mathbf{1 0 0 . 0}$ & $\mathbf{1 0 0 . 0}$ \\
\hline
\end{tabular}

FONTE: IBGE/PNAD.

Outra informação sobre o trabalho dos homens jovens que integram os dois GGAs cuja trajetória está sendo analisada diz respeito à jornada de trabalho. Computando todos os trabalhos, constata-se que o tempo parcial, forma amplamente utilizada em outros países para contratação - e precarização - do trabalho juvenil é pouco recorrente no Brasil. Entre 1992 e 2006, a proporção de jovens ocupados do sexo masculi- 
no que cumpriu jornada semanal inferior a 40 horas semanais foi pouco superior a $10 \%$ de cada grupo geracional. A única exceção ocorreu com o grupo de 15 a 19 anos em 1992 (GGA 1), com cerca de $20 \%$ com jornada parcial naquele ano. De outro lado, jornadas muito extensas, acima de 45 horas semanais, foram cumpridas pelos integrantes dos dois grupos ao longo das suas trajetórias ocupacionais e mais frequentes no final do período considerado, quando mais de $1 / 4$ deles, como visto entre os de 29 a 38 anos em 2006, trabalhava mais de 48 horas semanais.

QUADRO 3: JOVENS POR SEXO E IDADE, SEGUNDO FAIXAS DE RENDIMENTO, BRASIL URBANO, 2011

\begin{tabular}{|l|c|c|c|c|c|c|}
\hline & \multicolumn{3}{|c|}{ De 15 19 anos } & \multicolumn{3}{c|}{ De 20 a 24 anos } \\
\hline $\begin{array}{l}\text { Classes de } \\
\text { rendimento em } \\
\text { salários mínimos }\end{array}$ & Masculino & Feminino & Total & Masculino & Feminino & Total \\
\hline Sem rendimento & 7.6 & 5.0 & 6.6 & 2.0 & 2.0 & 2.0 \\
\hline $\begin{array}{l}\text { Até 1/2 salário } \\
\text { mínimo }\end{array}$ & 13.3 & 20.4 & 16.2 & 2.9 & 7.2 & 4.8 \\
\hline $\begin{array}{l}\text { Mais de 1/2 até 1 } \\
\text { salário mínimo }\end{array}$ & 33.6 & 34.8 & 34.1 & 20.6 & 27.1 & 23.4 \\
\hline $\begin{array}{l}\text { Mais de 1 até 2 } \\
\text { salários mínimos }\end{array}$ & 38.5 & 36.1 & 37.5 & 48.3 & 47.2 & 47.8 \\
\hline $\begin{array}{l}\text { Mais de 2 até 3 } \\
\text { salários mínimos }\end{array}$ & 4.2 & 1.4 & 3.1 & 15.7 & 9.0 & 12.8 \\
\hline $\begin{array}{l}\text { Mais de 3 até 5 } \\
\text { salários mínimos }\end{array}$ & 0.4 & 0.0 & 0.3 & 5.1 & 3.6 & 4.4 \\
\hline $\begin{array}{l}\text { Mais de 5 até 10 } \\
\text { salários mínimos }\end{array}$ & 0.2 & 0.0 & 0.1 & 1.7 & 0.9 & 1.4 \\
\hline $\begin{array}{l}\text { Mais de 10 até 20 } \\
\text { salários mínimos }\end{array}$ & 0.0 & 0.0 & 0.0 & 0.4 & 0.0 & 0.2 \\
\hline $\begin{array}{l}\text { Mais de 20 salá- } \\
\text { rios mínimos }\end{array}$ & 0.0 & 0.0 & 0.0 & 0.0 & 0.0 & 0.0 \\
\hline Sem declaração & 2.3 & 2.2 & 2.2 & 3.3 & 3.0 & 3.2 \\
\hline \multicolumn{1}{|c|}{ Total } & $\mathbf{1 0 0 . 0}$ & $\mathbf{1 0 0 . 0}$ & $\mathbf{1 0 0 . 0}$ & $\mathbf{1 0 0 . 0}$ & $\mathbf{1 0 0 . 0}$ & $\mathbf{1 0 0 . 0}$ \\
\hline
\end{tabular}

FONTE: IBGE/PNAD.

Essas extensas jornadas de trabalho contribuem para explicar o baixo percentual de jovens do sexo masculino que ainda freqüentava a escola a partir dos 19 anos e evidencia o elevado custo da combinação estudo-trabalho no Brasil, onde até mesmo no estágio profissionalizante —um dos principais mecanismos de precarização do trabalho 
juvenil e de burla da legislação trabalhista - eram comuns as jornadas de 40 horas semanais. ${ }^{13}$

Observe-se, finalmente, que as longas jornadas de trabalho vivenciadas pelos jovens dos dois grupos do início ao fim do período não lhes assegurou ganhos expressivos de remuneração. No final do período estudado, apesar da melhoria das condições do mercado de trabalho e de alguma recuperação dos salários, nos dois GGAs mais da metade dos homens ocupados que trabalhavam 40 horas ou mais por semana ganhava, no máximo, 2 salários mínimos, e a proporção dos que ganhavam até 3 salários mínimos correspondia a quase 3/4 do GGA 1 e a $69 \%$ do GGA 2. Além disso, apesar desses grupos serem, em média, mais escolarizados do que as gerações que os antecederam, apenas $5,5 \%$ e $4,5 \%$, respectivamente, eram formados por ocupados que, trabalhando uma jornada igual ou superior a 40 horas semanais, conseguiam rendimento mensal equivalente a 10 ou mais salários mínimos.

Controlando os rendimentos pela escolaridade alcançada vê-se que, em 2006, já na faixa etária de 29 a 33 anos, 56\% dos homens do GGA 1 que tinham completado o Ensino Médio ganhavam até 3 salários mínimos, faixa na qual eram encontrados $16 \%$ dos que tinham diploma universitário. No GGA 2 (34 a 38 anos em 2006) estes percentuais eram de, respectivamente, $50 \%$ e $12,9 \%$. Essa concentração nas faixas de rendimento mais baixas de homens adultos com escolaridade muito acima da média da população ativa é emblemática do perfil do mercado de trabalho brasileiro depois da reestruturação produtiva. Um perfil que se completa com as baixíssimas proporções representadas pelos integrantes dos GGAs estudados que lograram conquistar, na idade adulta, uma ocupação com remuneração superior a 10 salários mínimos: no GGA 1, 3,1\% dos que tinham diploma do ensino Médio e apenas $32,7 \%$ dos que tinham diploma universitário. No GGA 2, ganhavam mais de 10 salários mínimos $4 \%$ e $29,9 \%$ dos portadores dos diplomas citados, respectivamente.

\section{b) Trajetórias femininas}

A maioria dos estudos voltados para a análise da transição para a vida adulta tende a ressaltar um conjunto de mudanças que, historicamente,

13 Em 2008, uma nova regulação do estágio fixou em 30 horas semanais a carga horária máxima para este tipo de vínculo, 
remetem ao modelo masculino, o qual inclui a conclusão dos estudos seguida de inserção no mundo do trabalho, a saída da casa dos pais, casamento e constituição de uma nova família para o trabalho. No entanto, no caso das mulheres, o trânsito escola-trabalho nem sempre foi um marcador da entrada na vida adulta, sendo mais comum, nas gerações passadas, ${ }^{14}$ o casamento e a constituição de nova família como destino mais provável para as mulheres, após a conclusão dos estudos.

Por esta razão, se, para os homens, a comparação intergeracional contribui para a compreensão das mudanças nas formas e características da inserção dos jovens no mercado de trabalho, no caso das mulheres a análise tem que partir da reconfiguração da própria transição feminina, que a partir dos anos 1990 tende a se aproximar do modelo masculino, ainda que não de forma generalizada, mas preservando, na maioria dos casos, elementos do modelo tradicional, como a responsabilidade feminina pelas tarefas ligadas à reprodução. Começando pela relação escola-trabalho, ressaltam, em primeiro lugar, as marcadas diferenças entre as trajetórias femininas e masculinas. Como se observa no Quadro 4, nos dois GGAs e em todas as idades os percentuais de mulheres que trabalham — combinando ou não o trabalho com os estudos - são muito inferiores aos masculinos. Como visto, entre os adolescentes de 15 a 19 anos em 1992, a proporção de homens que já trabalhava era superior a $57 \%$ do grupo, enquanto entre as mulheres essa proporção era de apenas $34 \%$, o mesmo ocorrendo no grupo de 20 a 24 anos em 1992 (GGA 2), cujo percentual feminino (50,8\%) era muito inferior ao masculino $(80,6 \%)$. Essas diferenças se mantêm marcantes até o final do período estudado, quando as proporções de homens que trabalhavam alcançavam $89,5 \%$ do grupo mais jovem e $91,2 \%$ do mais velho, contra, respectivamente, apenas $61 \%$ e $67,8 \%$ entre as mulheres.

Observa-se, no entanto, na comparação entre as mulheres dos dois grupos, que para uma mesma faixa etária, no grupo mais jovem as proporções das que trabalham são sempre um pouco mais elevadas do que no grupo que tinha de 20 a 24 anos em 1992. Assim, em 2002, quando o GGA 1 alcançou a faixa de 25 a 29 aos de idade, 59\% das jovens estavam trabalhando, enquanto no GGA 2 , que havia atingido essas idades em 1997, a proporção de mulheres que trabalhava era de $54,6 \%$. Esse resultado pode estar embutindo algum efeito de período

14 Com importantes diferenças associadas à posição na estrutura sócioeconômica. 
- isto é, a conjuntura do mercado de trabalho quando cada um dos grupos estudados chegou a esta faixa etária.

QUADRO 4: INDICADORES DE ATIVIDADE, DESEMPREGO, FORMAS DE INSERÇÃO E RELAÇÃO TRABALHO/ESCOLA, MULHERES, GRUPOS GERACIONAIS SELECCIONADOS, BRASIL URBANO, 1992-2006

\begin{tabular}{|l|c|c|c|c|c|c|c|c|}
\hline IDADE EM 1992 & \multicolumn{5}{|c|}{$15 \mathbf{A ~ 1 9}$} & \multicolumn{4}{c|}{$\mathbf{2 0} \mathbf{A 2 4}$} \\
\hline Ano & $\mathbf{1 9 9 2}$ & $\mathbf{1 9 9 7}$ & $\mathbf{2 0 0 2}$ & $\mathbf{2 0 0 6}$ & $\mathbf{1 9 9 2}$ & $\mathbf{1 9 9 7}$ & $\mathbf{2 0 0 2}$ & $\mathbf{2 0 0 6}$ \\
\hline Idade & $\mathbf{1 5 - 1 9}$ & $\mathbf{2 0 - 2 4}$ & $\mathbf{2 5 - 2 9}$ & $\mathbf{2 9 - 3 3}$ & $\mathbf{2 0 - 2 4}$ & $\mathbf{2 5 - 2 9}$ & $\mathbf{3 0 - 3 4}$ & $\mathbf{3 4 - 3 8}$ \\
\hline $\begin{array}{l}\text { Taxa de ativi- } \\
\text { dade }\end{array}$ & 44.2 & 61.9 & 68.4 & 73.1 & 59.7 & 62.8 & 69.6 & 73.4 \\
\hline $\begin{array}{l}\text { Taxa de desem- } \\
\text { prego }\end{array}$ & 21.1 & 17.7 & 14.2 & 11.2 & 15.1 & 13.2 & 11.3 & 8.7 \\
\hline \% ECC & 26.9 & 46.8 & 45.8 & 46.1 & 49.2 & 47.7 & 44.2 & 43.1 \\
\hline \% ESC & 20.3 & 18.2 & 16.1 & 14.2 & 15.0 & 13.2 & 12.1 & 11.5 \\
\hline \% CP & 5.2 & 8.4 & 12.8 & 15.6 & 8.5 & 13.1 & 16.5 & 16.8 \\
\hline \% TD & 38.4 & 21.5 & 18.5 & 17.5 & 20.1 & 18.0 & 18.9 & 20.7 \\
\hline $\begin{array}{l}\text { \% Contribuin- } \\
\text { te*s }\end{array}$ & 9.4 & 27.4 & 34.2 & 38.4 & 27.6 & 30.8 & 35.2 & 39.3 \\
\hline Só estudam & 41.7 & 11.6 & 5.0 & 3.2 & 9.5 & 3.8 & 2.9 & 2.4 \\
\hline Só trabalham & 18.1 & 38.0 & 50.0 & 57.1 & 39.6 & 48.4 & 54.8 & 60.8 \\
\hline $\begin{array}{l}\text { Estudam e } \\
\text { trabalham }\end{array}$ & 16.8 & 13.1 & 9.0 & 7.8 & 11.2 & 6.2 & 7.1 & 6.3 \\
\hline $\begin{array}{l}\text { Não estudam } \\
\text { nem trabalham }\end{array}$ & 23.3 & 37.3 & 35.9 & 31.9 & 39.6 & 41.6 & 35.2 & 30.6 \\
\hline $\begin{array}{l}\text { ECC - Empregados com Carteira Assinada, Funcionários Públicos e Militares; ESC - } \\
\text { Empregados sem Carteira Assinada; CP - Conta Própria; TD - Trabalhadores Domés- } \\
\text { ticos; Contribuintes - Pessoas que contribuem para a previdência. }\end{array}$ \\
\hline
\end{tabular}

FONTE: IBGE/PNAD.

No que se refere à relação com o estudo, também entre as mulheres decresce rapidamente com o aumento da idade a proporção dos que estudam e, em especial, daqueles que «só estudam». Na faixa dos 20 aos 24 anos ainda estudavam, com ou sem a combinação com o trabalho, $21,7 \%$ das mulheres do grupo mais velho (GGA 2) e $24,7 \%$ das mulheres do grupo mais jovem (GGA 1), o que é coerente com a crescente valorização da educação - em especial dos diplomas do ensino médio e do superior - pelas famílias e pelo mercado e com as maiores oportunidades de acesso a estes níveis de ensino a partir dos anos 1990, o que tem beneficiado os mais jovens e as mulheres, que tendem a permanecer por mais tempo no sistema educacional.

Por fim, ao longo da trajetória dos dois grupos geracionais abertos estudados é muito mais elevada entre as mulheres do que entre os 
homens a proporção das que «não estudam nem trabalham», a qual atingia, em 2006, cerca de $30 \%$ das mulheres dos dois grupos geracionais, então com idades entre 29 e 38 anos. Tais percentuais são coerentes com as elevadas taxas de desemprego das mulheres jovens e parecem sugerir a persistência de relações de gênero tradicionais que reservam às mulheres as obrigações com as tarefas ligadas à reprodução, aprisionando-as no espaço privado.

Nesse sentido, seria interessante, por exemplo, indagar em que medida e em quais segmentos sociais as condições adversas do mercado de trabalho não estariam agindo no sentido de levar uma parcela das mulheres jovens a reproduzirem a trajetória das suas mães. Informações mais detalhadas sobre as jovens que não estudam nem trabalham, apresentadas mais à frente, corroboram a hipótese da persistência, no século XXI, do padrão tradicional de transição feminina para uma parcela significativa das mulheres jovens.

Além dessa, outras hipóteses podem ser exploradas para explicar o elevado percentual de adultas jovens que não estudavam nem trabalhava em 2006, como, por exemplo, a de que uma parcela desse contingente seja composto por jovens que estão se preparando para concurso ou se qualificando para disputar um emprego com maiores chances de sucesso ${ }^{15}$; por um número crescente de mulheres jovens em situação de risco, inclusive vivenciando experiências semelhantes às masculinas ${ }^{16} \mathrm{e}$, também, por indivíduos portadores de deficiências incapacitantes, hipóteses que devem ser consideradas também na explicação do elevado percentual de homens jovens que não estudam nem trabalham.

Apesar de tudo isso, é inegável que nos anos 1990 ocorreu uma entrada maciça das mulheres no mercado de trabalho, intensificando um processo que no Brasil metropolitano já se tornara marcante na década de 1980. Em 1992, a participação das mulheres jovens na população economicamente ativa já era significativa, como se vê na Quadro 3: no GGA 1 (adolescentes de 15 a 19 anos) a taxa de atividade era de 44,2\% e no GGA 2 (jovens de 20 a 24 anos) ela alcançava quase $60 \%$. Tais taxas

15 Não esquecer que a frequiência à escola captada pela PNAD não inclui uma série de cursos de especialização, de complementação e de atualização da formação escolar, nem os cursos preparatórios para concursos, uma «atividade» à qual vem se dedicando, com exclusividade, uma parcela não medida dos jovens brasileiros pertencentes a famílias dos estratos de renda mais elevados.

16 Trata-se de um fenômeno que ganha visibilidade já desperta o interesse de pesquisadores. Ver, por exemplo, Abramovay, 2010. 
estão quase 20 pontos percentuais abaixo das masculinas e esta diferença se mantém até 2006, quando as jovens de 1992 já tinham atingido a idade adulta (29 a 33 anos no GGA 1 e 34 a 38 no GGA 2).

Coerente com o que foi ressaltado anteriormente na análise dos dados sobre a relação trabalho-estudo, observa-se também que as mulheres do grupo mais jovem, ao alcançarem idades já ultrapassadas pelo grupo mais velho, apresentam taxas de atividade mais elevadas, outro indicativo da sustentação da tendência ao aumento da pressão feminina sobre o mercado de trabalho, apesar do maior tempo de permanência na escola das mulheres das gerações mais novas. Parece, portanto, que apesar do ainda elevado percentual de jovens do sexo feminino que não estudam nem trabalham, está se configurando para as mulheres um padrão semelhante ao observado para os homens, no qual, após a adolescência, a continuidade dos estudos na maioria dos casos vem acompanhada do trabalho, fenômeno que é coerente com a pobreza da maior parte das famílias e com o fato de que são exatamente os jovens mais pobres os que têm se beneficiado da recente expansão das oportunidades de acesso a níveis de escolaridade mais elevados.

No contexto de uma reestruturação produtiva fortemente centrada na redução de custos, sobretudo os do trabalho, essa pressão feminina traduziu-se no aumento da proporção de mulheres na ocupação total (em 2006, nos dois GGAs estudados, as mulheres já representavam cerca de $45 \%$ dos ocupados). Mas resultou igualmente em elevadas taxas de desemprego, sempre muito superiores às masculinas. Em 2006, no grupo mais jovem, então com idades de 29 a 33 anos, a taxa feminina era de $11,2 \%$ contra apenas $5,2 \%$ para os homens; no grupo mais velho - 34 a 38 anos - as taxas eram de, respectivamente, $8,7 \%$ e 4,2\%. Além disso, como mais um indicador a confirmar os estudos que têm mostrado que as mulheres vêm arcando com uma parcela maior do ônus da crise do mercado de trabalho, à medida que os dois GGAs avançam para a idade adulta, aumenta a proporção representada pelas mulheres no contingente de desempregados até alcançar, em 2006 , quase $65 \%$ dos desempregados de cada grupo.

A desvantagem feminina é visível também no perfil da inserção das jovens no mercado de trabalho. Nos dois GGAs, a proporção delas que tinha, em 2006, um emprego com proteção social estava quase 10 pontos percentuais abaixo doa posição masculina. Também são sempre inferiores aos dos homens os percentuais de mulheres em empregos Sem Carteira Assinada ou por Conta Própria, duas posições que concentram ocupações precárias, mas, neste caso, a baixa presença feminina 
resulta, principalmente, da importância que ainda tem para as jovens o Trabalho Doméstico, outro tipo de inserção marcado pela precariedade.

Trabalho Doméstico, pois embora esta atividade ainda incorpore uma proporção elevada de mulheres jovens nas áreas urbanas do país, os dois GGAs estudados já apresentam comportamentos diferentes: enquanto no grupo mais velho (20 a 24 anos em 1992) a proporção de Trabalhadoras Domésticas se mantém relativamente estável -em torno de 20\% - ao longo do período analisado, no grupo mais jovem, apesar do elevadíssimo percentual de mulheres nesta ocupação em 1992, esta proporção cai rapidamente à medida que o grupo se aproxima da idade adulta. Devem estar contribuindo para esta queda tanto uma rejeição das gerações mais novas e mais escolarizadas a este tipo de trabalho - que historicamente se constituiu em uma das poucas opções das mulheres pobres e com poucos anos de estudo-, como uma redução da demanda provocada pelo empobrecimento dos estratos médios a partir dos anos 1990.

A maior precariedade da inserção feminina retratada nesses indicadores, como não poderia deixar de ser, vai implicar em maior desproteção presente e futura. Nos dois GGAs, ao atingirem a idade adulta (em torno de 30 anos), o percentual de mulheres que contribuía para a previdência situava-se quase 20 pontos percentuais abaixo do patamar masculino: $34,7 \%$ e $57,9 \%$ no GGA 1 e $35,2 \%$ e $579 \%$ no GGA 2 . Outro aspecto da inserção feminina refere-se à extensão da jornada de trabalho: para a maioria das mulheres dos dois grupos (entre $76 \%$ e $66 \%$ ) o trabalho implica em comprometimento com jornadas de trabalho que ultrapassam as 40 horas semanais, embora esses percentuais sejam inferiores aos masculinos.

Ressalte-se porém que diferentemente dos homens, cujas horas de trabalho semanais aumentam com a aproximação da idade adulta, entre as mulheres elas caem à medida que se aproximam as idades em que a maioria delas se casa e tem filhos. No grupo mais velho, as jornadas mais extensas são registradas nas idades de transição da adolescência para a juventude (15 a 19 anos) e no grupo mais jovem, até a faixa de 20 a 24 anos, caindo a partir dai o percentual de mulheres que trabalham muito além das 40 horas semanais. 
QUADRO 5: HORAS TRABALHADAS EM TODOS OS TRABALHOS, MULHERES, GRUPOS GERACIONAIS SELECIONADOS, BRASIL URBANO, 1992-2006

\begin{tabular}{|l|c|c|c|c|c|c|c|c|}
\hline \multicolumn{7}{|c|}{ Grupos Geracionais } \\
\hline & \multicolumn{7}{|c|}{15 a 19 anos em 1992 } & \multicolumn{3}{c|}{ 20 a 24 anos em 1992 } \\
\hline Ano & $\mathbf{1 9 9 2}$ & $\mathbf{1 9 9 7}$ & $\mathbf{2 0 0 2}$ & $\mathbf{2 0 0 6}$ & $\mathbf{1 9 9 2}$ & $\mathbf{1 9 9 7}$ & $\mathbf{2 0 0 2}$ & $\mathbf{2 0 0 6}$ \\
\hline Idade & $\mathbf{1 5 - 1 9}$ & $\mathbf{2 0 - 2 4}$ & $\mathbf{2 5 - 2 9}$ & $\mathbf{2 9 - 3 3}$ & $\mathbf{2 0 - 2 4}$ & $\mathbf{2 5 - 2 9}$ & $\mathbf{3 0 - 3 4}$ & $\mathbf{3 4 - 3 8}$ \\
\hline $\begin{array}{l}\text { Horas } \\
\text { trabalhadas }\end{array}$ & & & & & & & & \\
\hline $\begin{array}{l}\text { Até 14 } \\
\text { horas }\end{array}$ & 5.0 & 4.1 & 5.8 & 6.3 & 4.6 & 5.8 & 6.2 & 6.7 \\
\hline $\begin{array}{l}\text { De 15 a 39 } \\
\text { horas }\end{array}$ & 23.6 & 22.0 & 24.7 & 25.9 & 23.0 & 25.1 & 26.9 & 26.8 \\
\hline $\begin{array}{l}\text { De 40 a 44 } \\
\text { horas }\end{array}$ & 30.1 & 38.2 & 36.6 & 37.5 & 37.8 & 37.3 & 35.6 & 36.0 \\
\hline $\begin{array}{l}\text { De 45 a } 48 \\
\text { horas }\end{array}$ & 18.0 & 18.1 & 16.5 & 14.5 & 17.1 & 15.0 & 14.2 & 14.3 \\
\hline $\begin{array}{l}\text { Mais de } 48 \\
\text { horas }\end{array}$ & 23.3 & 17.5 & 16.3 & 15.7 & 17.4 & 16.7 & 17.0 & 16.2 \\
\hline Total & $\mathbf{1 0 0 . 0}$ & $\mathbf{1 0 0 . 0}$ & $\mathbf{1 0 0 . 0}$ & $\mathbf{1 0 0 . 0}$ & $\mathbf{1 0 0 . 0}$ & $\mathbf{1 0 0 . 0}$ & $\mathbf{1 0 0 . 0}$ & $\mathbf{1 0 0 . 0}$ \\
\hline
\end{tabular}

FONTE: IBGE/PNAD.

As desigualdades de gênero no interior dos dois grupos geracionais abertos tornam-se mais evidentes quando observados os rendimentos do trabalho. Entre as mulheres a concentração de ocupadas nas classes de renda mensal mais baixa é ainda mais forte do que entre os homens, mesmo quando considerados apenas aqueles que cumprem jornadas de trabalho de 40 horas ou mais (quadro 3). A desigualdade ocorre também entre aqueles com escolaridade elevada: em 2006, a proporção de mulheres com diploma universitário ganhando, no máximo, até 3 salários mínimos e com jornada igual ou superior a 40 horas semanais é duas vezes maior do que entre os homens, nos dois GGASs enquanto a proporção de homens que consegue ganhar mensalmente 10 ou mais salários mínimos é 2,6 vezes superior à proporção de mulheres.

A análise das trajetórias masculinas e femininas dos jovens sugere, portanto, que no conjunto do Brasil urbano as desigualdades de gênero no mercado de trabalho ainda são marcantes, acompanham a entrada maciça de mulheres na esfera da produção e, apesar das conquistas femininas no âmbito da educação, vêm se reproduzindo nas novas gerações. 


\section{c) Panorama do trabalho juvenil em 2011}

Analisadas as trajetórias dos dois grupos jovens de 1992 a 2006, resta observar a inserção dos mesmos grupos etários em 2011, captando o impacto do conjunto de transformações do período analisado e da segunda metade dos anos 2000: a reestruturação produtiva, o ciclo de crescimento com geração de empregos dos anos 2000, o fim do fenômeno demográfico que ficou conhecido como onda jovem e a acelerada expansão da escolaridade das novas gerações.

QUADRO 6: INDICADORES DE ATIVIDADE, DESEMPREGO, FORMAS DE INSERÇÃO E RELAÇÃO TRABALHO/ESCOLA, HOMENS, GRUPOS GERACIONAIS SELECIONADOS, BRASIL URBANO, 2011

\begin{tabular}{|l|c|c|c|c|}
\hline IDADE EM 2011 & \multicolumn{2}{|c|}{ 15 A 19 } & \multicolumn{2}{c|}{ 20 A 24 } \\
\hline & Homens & Mulheres & Homens & Mulheres \\
\hline Taxa de atividade & 47.4 & 36.1 & 85.6 & 68.5 \\
\hline Taxa de desemprego & 19.5 & 28.5 & 10.4 & 16.7 \\
\hline \% ECC & 43.4 & 43.6 & 64.0 & 61.6 \\
\hline \% ESC & 43.4 & 32.9 & 22.6 & 19.9 \\
\hline$\%$ CP & 5.1 & 4.8 & 10.0 & 6.5 \\
\hline Só estudam & 49.6 & 55.6 & 8.6 & 12.0 \\
\hline Só trabalham & 19.8 & 12.0 & 63.4 & 42.9 \\
\hline Estudam e trabalham & 18.4 & 13.9 & 13.4 & 14.1 \\
\hline $\begin{array}{l}\text { Não estudam } \\
\text { nem trabalham }\end{array}$ & 12.2 & 18.5 & 14.7 & 31.0 \\
\hline $\begin{array}{l}\text { ECC - Empregados com Carteira Assinada, Funcionários Públicos e Militares; ESC - } \\
\text { Empregados sem Carteira Assinada; CP - Conta Própria; }\end{array}$ \\
\hline
\end{tabular}

FONTE: IBGE/PNAD.

Quanto à participação juvenil no mercado de trabalho destacam-se, primeiramente, as marcadas diferenças entre os dois grupos etários e entre homens e mulheres. Os adolescentes e jovens entre 15 e 19 anos de idade, ambos os sexos, reduzem significativamente as suas taxas de atividade (de 67,9\% em 1992 para 47,4\% em 2011, no caso dos homens e de $47,4 \%$ para $36,1 \%$ as mulheres) assim como os percentuais daqueles que têm no trabalho sua única atividade e dos que acumulam Estudo e trabalho. Em contrapartida, aumentam as proporções de adolescentes e jovens entre 15 e 19 anos que Só estudam. Este indicador confirma a tendência ao adiamento da idade de entrada no mercado de trabalho, a qual resulta da conjugação de uma série de fatores: redução do número médio de filhos o que amplia as possibili- 
dades de maiores investimento das famílias nas crianças e jovens; melhoria significativa da renda dos segmentos mais empobrecidos, permitindo que parte das famílias nesta situação possa dispensar a contribuição dos seus filhos mais novos para assegurar o seu sustento; ampliação da oferta de vagas gratuitas nos sistema de ensino público e privado e as exigências crescentes de mais escolaridade por parte dos empregadores.

Observe-se, no entanto, que nesses quase 20 anos, simultaneamente dois outros indicadores relativos aos adolescentes e jovens entre 15 e 19 anos evoluíram negativamente. A taxa de desemprego aberto cresceu para homens e mulheres, apesar da queda da taxa de atividade (menor pressão da oferta); da recuperação da economia e da abertura de novos postos de trabalho, apontando para a exclusão do mercado de trabalho de segmentos importantes da força de trabalho juvenil nessa faixa etária (19,5\% dos homens e $28,5 \%$ das mulheres). Além disso, o percentual de cada grupo etário que nem estuda nem trabalha também cresceu para homens. Já o grupo etário de 20 a 24 anos apresenta diferenças importantes entre os sexos. De uma maneira geral, cai a participação masculina no mercado de trabalho e os percentuais dos que trabalham, combinando ou não esta atividade com os estudos, enquanto entre as mulheres o movimento é o inverso: as taxas de atividade são bem mais elevadas do que em 1992, assim como também são mais elevados os percentual das jovens que trabalham e que estudam e trabalham.

Apesar disso, em 2011, entre os homens jovens de 20 a 24 anos, o desemprego se mantém relativamente estável no patamar de 1992, depois de ter oscilado bastante ao longo dos 19 anos considerados, mas o percentual daqueles que não estudam nem trabalho passa de 13,4\% em 1992 para 14,7\% em 2011, evidenciando que o afastamento de contingentes significativos de jovens do trabalho e da escola, revelado nas trajetórias, independe da conjuntura macroeconômica e até certo ponto do próprio mercado de trabalho, constituindo-se em um fenômeno complexo, cujas determinações não se originam apenas das características do mercado de trabalho mas, também, do perfil familiar, da qualidade da escola, da segregação urbana, da sociabilidade violenta, etc.

No caso das mulheres, em 2011, a taxa de desemprego mantémse bastante elevada $(16,7 \%)$ e o percentual daquelas que não estudam nem trabalham caiu de 39,6\% em 1992 para 31,0\% em 2011. Apesar desta queda, o fato de quase $1 / 3$ das jovens entre 20 e 24 anos não 
trabalhar nem estudar indica a persistência de valores tradicionais que atribuem às mulheres um papel central nas atividades ligadas à reprodução e, também, a ausência ou ineficácia das políticas públicas voltadas para atenção à primeira infância, como creches públicas e nos locais de trabalho.

Alguns dados sobre o perfil das jovens que Não estudam nem trabalham, apontam as responsabilidades familiares como principal obstáculo à continuidade dos estudos e à inserção no mercado de trabalho. Assim, segundo a PNAD, em 2011, para ambos os grupos etários, a proporção das jovens que ocupavam a posição de Pessoa de Referência na família eram mais elevadas entre as aquelas que Não estudavam nem trabalhavam do que na média do grupo etário: entre 15 a 19 anos $12,9 \%$ e 5,1\%, respectivamente e no grupo de 20 a 24 esses percentuais eram de $19,6 \%$ e $16,2 \%$. Tais diferenças são ainda mais acentuadas quando considerado o percentual das jovens que declararam ocupar a posição de Cônjuge: nada menos do que 25,6\% das jovens nem-nem, no grupo de 15 a 19 anos (média de 9,1\%), e 42,6\% entre as jovens nem-nem no grupo de 20 a 24 anos (média de 29,2\%).

Outro indicador, o número médio de horas semanais dedicadas aos afazeres domésticos mostra que ele é algo mais elevado entre as jovens que Não estudam nem trabalham do que na média de cada grupo etário mas, neste caso, independe da posição na família, isto é todas as jovens que Não estudam nem trabalham acabam assumindo uma carga maior de responsabilidade nas tarefas domésticas. É curioso observar, no entanto, que estas diferenças de número de horas dedicadas ao trabalho doméstico entre as jovens que estudam e/ou trabalham e as nem-nem não são muito expressivas, o que só retrata a persistência das desigualdades de gênero na partilha do trabalho voltado para a reprodução.

Estes achados a partir dos dados da PNAD são corroborados por pesquisa da OIT sobre a transição da escola para o trabalho. ${ }^{17}$ Analisando a situação dos nem-nem, o estudo constata que, entre estes jovens, em maior proporção do que os homens, as mulheres abandonaram os estudos antes de concluí-los e afirma que «o principal determinante dessas diferenças por sexo decorre, sobretudo, da entrada das mulheres jovens mais cedo em relações maritais, e na maternidade, resultante dessa trajetória tradicional de gênero» (Venturi e Torini, 2014:52).

17 O relatório desta pesquisa está disponível em: www.ipea.gov.br. 
QUADRO 7: MULHERES POR CONDIÇÃO NA FAMÍLIA E HORAS TRABALHADAS EM AFAZERES DOMÉSTICOS, SEGUNDO GRUPOS ETÁRIOS SELECIONADOS, QUE ESTÃO DESOCUPADAS OU NÃO ECONOMICAMENTE ATIVAS E NÃO FREQUENTAM ESCOLA, BRASIL URBANO, 2011

\begin{tabular}{|l|c|c|c|c|}
\hline Faixas etárias & \multicolumn{2}{|c|}{15 a 19 anos } & \multicolumn{2}{c|}{20 a 24 anos } \\
\hline Condição na família & Total & Nem nem & Total & Nem nem \\
\hline Pessoa de referência & 25 & 30 & 25 & 34 \\
\hline Cônjuge & 29 & 33 & 30 & 38 \\
\hline Filho & 16 & 20 & 15 & 21 \\
\hline Outro parente & 18 & 24 & 18 & 24 \\
\hline Agregado & 19 & 27 & 17 & 24 \\
\hline Pensionista & 14 & 15 & 10 & 10 \\
\hline
\end{tabular}

FONTE: IBGE/PNAD.

Quanto à qualidade da inserção juvenil em mercados de trabalho flexibilizados e reestruturados como os mercados urbanos do Brasil no início da segunda década d século XXI, observa-se, em primeiro lugar, que os jovens beneficiaram-se da expansão dos opostos de trabalho protegidos. Para os dois grupos etários e para ambos os sexos ocorre uma elevação do percentual de jovens com emprego formalizado, o qual alcançava, em $2011,64,0 \%$ dos homens e $61,6 \%$ das mulheres. O maior acesso dos jovens aos postos de trabalho protegidos foi suficiente para reduzir significativamente os contingentes submetidos a formas precárias de inserção. Assim, em 2011, cerca de 43\% dos adolescentes e jovens do sexo masculino que tinham entre 15 e 19 anos permanecia em empregos desprotegidos e entre os jovens de 20 a 24 anos o percentual dos empregados sem registro era de $22,6 \%$, aos quais se somavam cerca de 10 na condição Conta Própria. No caso das mulheres, a desproteção do vínculo empregatício se amplia entre 1992 e 2011, sobretudo no caso do grupo etário de 15 a 19 anos, quando chega a atingir cerca de 1/3 do grupo.

Além da persistência dos contingentes desprotegidos, outro indicador evidencia que a inserção juvenil nos mercados de trabalho urbanos do Brasil é marcada pela precariedade, mesmo com a expansão do chamado «emprego com carteira assinada»: em 2011, apesar de apresentarem escolaridade bem mais elevada do que a dos dois grupos geracionais estudados, $73,8 \%$ dos homens e $83,5 \%$ das mulheres entre 20 e 24 anos ganhavam, no máximo dois salários mínimos e apenas $3,7 \%$ dos homens e 3\% das mulheres ganhavam dez ou mais salários mínimos. 
QUADRO 8: JOVENS POR SEXO E IDADE, SEGUNDO FAIXAS DE RENDIMENTO, BRASIL URBANO, 2011

\begin{tabular}{|c|c|c|c|c|c|c|}
\hline & \multicolumn{3}{|c|}{ De 15 a 19 anos } & \multicolumn{3}{|c|}{ De 20 a 24 anos } \\
\hline $\begin{array}{l}\text { Classes de } \\
\text { rendimento em } \\
\text { salários } \\
\text { mínimos }\end{array}$ & Masculino & Feminino & Total & Masculino & Feminino & Total \\
\hline Sem rendimento & 7.6 & 5.0 & 6.6 & 2.0 & 2.0 & 2.0 \\
\hline $\begin{array}{l}\text { Até } 1 / 2 \text { salário } \\
\text { mínimo }\end{array}$ & 13.3 & 20.4 & 16.2 & 2.9 & 7.2 & 4.8 \\
\hline $\begin{array}{l}\text { Mais de } 1 / 2 \text { até } \\
1 \text { salário } \\
\text { mínimo }\end{array}$ & 33.6 & 34.8 & 34.1 & 20.6 & 27.1 & 23.4 \\
\hline $\begin{array}{l}\text { Mais de } 1 \text { até } 2 \\
\text { salários } \\
\text { mínimos }\end{array}$ & 38.5 & 36.1 & 37.5 & 48.3 & 47.2 & 47.8 \\
\hline $\begin{array}{l}\text { Mais de } 2 \text { até } 3 \\
\text { salários } \\
\text { mínimos }\end{array}$ & 4.2 & 1.4 & 3.1 & 15.7 & 9.0 & 12.8 \\
\hline $\begin{array}{l}\text { Mais de } 3 \text { até } 5 \\
\text { salários } \\
\text { mínimos }\end{array}$ & 0.4 & 0.0 & 0.3 & 5.1 & 3.6 & 4.4 \\
\hline $\begin{array}{l}\text { Mais de } 5 \text { até } 10 \\
\text { salários } \\
\text { mínimos }\end{array}$ & 0.2 & 0.0 & 0.1 & 1.7 & 0.9 & 1.4 \\
\hline $\begin{array}{l}\text { Mais de } 10 \text { até } \\
20 \text { salários } \\
\text { mínimos }\end{array}$ & 0.0 & 0.0 & 0.0 & 0.4 & 0.0 & 0.2 \\
\hline $\begin{array}{l}\text { Mais de } 20 \\
\text { salários míni- } \\
\text { mos } \\
\end{array}$ & 0.0 & 0.0 & 0.0 & 0.0 & 0.0 & 0.0 \\
\hline Sem declaração & 2.3 & 2.2 & 2.2 & 3.3 & 3.0 & 3.2 \\
\hline Total & 100.0 & 100.0 & 100.0 & 100.0 & 100.0 & 100.0 \\
\hline
\end{tabular}

FONTE: IBGE/PNAD.

Resta evidente, portanto, que na análise da inserção dos jovens, o foco nas condições de trabalho é tão importante quanto a observação do desemprego, pois embora com o passar dos anos a maioria tenha escapado do desemprego, uma parcela importante dos grupos geracionais estudados acabou tendo como o destino final postos de trabalho precários e, apesar do dinamismo do mercado de trabalho brasileiro na primeira década do século XXI, a maioria dos jovens que trabalham recebe salários muito baixos. Como explica Pascual (1995), com o avanço da idade aumentam as pressões para a superação da condição juvenil, 
o que, para muitos, significa submeter-se à precariedade e aos baixos rendimentos que não asseguram a emancipação necessária para completar a transição para a vida adulta, com a saída da casa dos pais e com a constituição de nova família.

Os indicadores analisados sugerem que no início do século XXI, um conjunto de fatores está contribuindo para o prolongamento do tempo de sucessão das gerações (Adeodato, 2005), em especial no mercado de trabalho: elevação da expectativa de vida e mudanças culturais que redefinem o significado da velhice e a postura das novas gerações de velhos; mudanças no sistema previdenciário que levam à postergação do momento de usufruto da aposentadoria; queda nos rendimentos do trabalho e baixa remuneração dos mais jovens, que forçam a permanência dos mais velhos no trabalho; e as exigências de escolarização crescentes, que levam as famílias a investirem mais na educação dos filhos, procurando garantir que eles permaneçam o maior tempo possível na escola.

Desse modo, em vários espaços de um mercado de trabalho ainda restrito, em rápida mutação e sem uma expansão significativa e sustentada de postos de trabalho que correspondam ao perfil e às expectativas das novas gerações de trabalhadores, muito mais escolarizadas do que as que as precederam, jovens e velhos, pais e filhos estão entrando em competição. Com isso, uma parcela dos jovens está sendo forçada a uma longa espera, que pode resultar em uma inserção tardia, mas, também, em perda das qualificações adquiridas, no aprisionamento em ocupações precárias e no desalento, com conseqüências sociais e pessoais extremamente graves.

SALVADOR (BRASIL), DICIEMBRE 2015

RECIBIDO: MARZO 2016

ACEPTADO: MAYO 2015 


\section{REFERÊNCIAS}

ABramovay, MiRIAM (Org.) (2010): Gangues, gênero e juventudes. Brasília: Donas de Rocha e Sujeitos Cabulosos, CUFA/Secretaria de Direitos Humanos.

ADEODATO, GUARACI (2005): «Implicações sociais dos novos padrões de reprodução demográfica na Bahia». Caderno CRH, Salvador, Vol. 18, №43.

Borges, Angela (2001): A inserção dos jovens baianos no mercado de trabalho nos anos 90: 10 anos do estatuto da criança e do adolescente., Salvador: UNICE/MOC.

Bourdieu, Pierre (1983): «A juventude é apenas uma palavra», in P. BouRdieu (Org.): Questões de sociologia. Rio de Janeiro: Marco Zero.

CARdoso, AdAlBerto (2007): Transição da escola para o trabalho: persistência da desigualdade e frustração de expectativas. Mimeo.

DRUCK, GRAÇA (1999): Terceirização: (des)fordizando a fábrica. Salvador: EDUFBA/Boitempo.

GuimarÃes, NADIA ARAuJO (2004): Caminhos cruzados: estratégias de empresas e trajetórias de trabalhadores. São Paulo: Editora $\mathrm{N}^{\circ} 34$.

LANGEVIN, ANNETE (1998): «A construção social das idades: mulheres adultas de hoje e velhas de amanhã». Caderno $C R H$, Salvador, №29.

OfFe, Claus (1989): Capitalismo desorganizado. São Paulo: Brasiliense.

PASCUAL, AMPARO SERRADO (1995): «Processos paradojicos de construccion de la juventud en un contexto de crisis del mercado de trabajo». Revista Española de Investigaciones Sociológicas No71/72.

POCHMANN, MÁRCIO (1998): Emprego e desemprego juvenil no Brasil: as transformações nos anos 90. Campinas: UNICAMP/IE/CESIT.

Telles, VerA (2006): «Mutações do trabalho e experiência urbana». Tempo Social, Vol. $18, \mathrm{~N}^{\circ} 1$.

DRUCK, GRAÇA y TÂNIA FRANCO (Org.) (2007): A perda da razão social do trabalho: terceirização e precarização. São Paulo: Boitempo.

VENTURI, GustaVo e DANILO TORINI (2014): Transições da escola para o trabalho dos jovens homens e mulheres no Brasil. Genebra: OIT.

Wajnman, Simone e AnA Flávia Machado (Orgs.) (2003): Mercado de trabalho: um análise a partir das pesquisas domiciliares. Belo Horizonte: Editora UFMG. 